\title{
From the Ivory Tower to Activity Based Workspaces
}

\author{
Dolly Samson
}

\begin{abstract}
In a typical university, a fulltime instructor teaches from three to fifteen hours a week. For a teaching university, this may even be as much as eighteen hours a week, up to $50 \%$ of the standard working time. During non-classroom hours, an instructor has many duties - advising students, committee meetings, conducting research, evaluating student work, and preparing for future class meetings, as well as serving as a community liaison. Much of the time, an instructor's office remains empty - a place simply to store books and papers. With a large proportion of empty offices during teaching times, and with a faculty becoming more technology-savvy, combined with perennially decreasing education budgets, it makes sense to revisit the traditional, cellular faculty office (the ivory tower) and consider alternatives that can both maintain a good academic workspace and make optimal use of resources (activity-based workspaces, or ABW). Unfortunately, many instructors loathe giving up their traditional office space, as it signifies status as well as a sanctuary away from students and colleagues. The tension between collaboration and privacy is difficult to resolve. As academic models change, case studies and best practices of successful projects present a path to faculty ABW. This paper reviews the academic tradition of a single or shared, enclosed university office space. It takes a forward-looking approach to activity-based workspaces- a concept that will be commonplace in the coming decade as Millenials start academic careers - and reviews supporting practices in industry as well as academia. Finally, this paper presents best practices and recommendations for transitioning faculty to open, shared and non-territorial workspaces.
\end{abstract}

Index Terms-Activity based workspace, faculty office, shared workspace.

\section{INTRODUCTION}

Walk down any hall in a conventional faculty office building, and many of the doors are closed and offices empty. Instructors spend anywhere from $10 \%$ to $50 \%$ of their working hours in the classroom, other time consumed by meetings, research and outside visits. Offices provide a quiet refuge where professors can work uninterrupted and where books and papers can be stored, sometimes for decades. In an era when university budgets are diminishing, where real estate is scarce and expensive, and where Millenials are quite comfortable communicating via technology, an examination of the need for traditional faculty offices seems necessary.

Recently, a colleague described her office at a private university in South East Asia as follows:

"At [University X], we all have nice private offices. Each teacher gets 1 office to him/herself, with a nice view too! We

Manuscript received May 10, 2013; revised July 10, 2013.

Dolly Samson is with the Stamford International University, Bangkok, Thailand (e-mail: dolly@stamford.edu). have to teach 9 hours of class per week (3 courses, each course is 3 hours), and we have to schedule 9 hours/week as "office hours." But no one ever comes to meet us. We just need to be somewhere around there, e.g. in the canteen, in the toilet, in the printer room etc. during those hours. But they can be rescheduled. Most teachers turn up just for office hours, and no more. Some don't really bother to come, cos [sic] there's no visitor. They usually go there just a little before class to prepare things, and sit in the office a little bit after class, e.g. to put things away, have a cup of tea, do Emails, mark attendance in the computer system etc." [1].

While extreme, the description is not unusual. The private, or semi-private, office is the norm. New university professors eagerly await their office assignment. The private office is a plum assignment, and a private office with a window is a sign of significant importance. Faculty office space is managed by deans and vice presidents, as the office assignment tells the world how relevant that professor is to the university and to their discipline. Universities use office space as a perk in recruiting the best professors. For example, the University of Maryland (US) says, "Each member of the regular faculty has an office on the 2nd or 4th floor of Hornbake Building, South Wing or in Building III at the Universities of Shady Grove" [2]. DLC+A, a campus and facility planning consultancy, states that they have 18,000 faculty offices in their space allocation database, with an average space of 163 square feet [3]. Universities continue to construct new office space. According to the "Building and Grounds" section of the Chronicle of Higher Education [4], the University of Michigan at Ann Arbor built 200 new faculty offices in 2010, Claremont McKenna College received a \$75M gift for classrooms, research institutes and faculty offices in 2007 , and Brigham Young University built 70 faculty offices in 2004.

Consider that a typical professor spends between three hours (one course) and fifteen hours (five courses) in the classroom each week. With the median of three classes, or nine hours per week in a classroom, this leaves an office, or office space vacant $25 \%$ of the work week, Monday to Friday. The percentage goes even higher for campuses with weekend classes. And according to UK utilization study [5] academics and researchers typically occupy their workspace for only 30 to $40 \%$ of the work day. There is much online discussion about the advantages of silence and privacy versus collaboration and cross-fertilization of ideas, and a dearth of research on the utility of activity-based workspaces in higher education. Most organizations reporting on $\mathrm{ABW}$ are commercial organizations including Kellogg's offices in Madrid, Spain; Microsoft in Netherlands; Commonwealth Bank of Australia, Sydney; and KIXEYE Online Gaming, San Francisco.

We are seeing a shift in teaching styles from the "sage on 
the stage" to the "guide by the side," where student-centered learning as a pedagogical practice focuses more on the needs of the students rather than teachers and administrators. The shift from a centuries-old model of lectures to one of facilitation hasn't always been simple. For example, student-centered learning was not fully incorporated into the European Union's Bologna Process until 2009 [6]. As teaching and learning become more student-centered, collaborative and technology supported, the ways faculty use space outside the classroom need to be studied to assure they align with the pedagogies and spaces for students.

In a recent study of faculty at a large U.S. university, [7] the author interviewed sixteen instructors about their work environments. The interviews examined "the dynamic relationship between what faculty do (practices), where they work (material place and social space) and who they are (professional identify)". The study revealed several contradictions between administrative expectations and instructor needs. For example, faculty members are assessed and promoted based, in part, on single-author publications, yet collaboration in teaching and research takes on a more significant role; the faculty cited a need for private space to read and write, yet they decried the disappearance of public areas on campus. Faculty consistently reported a separation of work activities based on location as well as ownership: research (their own work) was typically done off-campus and administrative duties (university work, including teaching) done on-campus.

\section{ACTIVITY-BASED WORKSPACES}

Activity-based workspace (ABW) is a concept that is growing in public and private organizations. Organizations in Australia, UK and the Netherlands have reported how they converted former cellular office space into non-territorial, activity-based spaces. ABW provides employees with a variety of activity areas where they can do different kinds of work, with "home zones" where work teams are centered but not anchored. ABW includes the freedom to work from home, and appraisal is based on work outputs rather than on work behaviors. ABW also needs competent IT support for mobility, and information security is paramount. Some key features of $\mathrm{ABW}$ include:

- Open, informal meeting spaces

- Enclosed conference rooms of different sizes

- Individual cabins

- Quiet reading areas

- Cafes

- Personal, secure storage lockers

- Sliding walls with writable surfaces

Negative aspects of ABW include people leaving a dirty workspace, lack of personalization in the space, and difficulty adjusting to different colleagues and different spaces on a regular basis.

In a recent study of eleven Australian organizations, none of them in higher education, that have either fully adopted or are piloting $\mathrm{ABW}$ [8], the top five positive outcomes include talent management, environmental responsibility, customer engagement, risk management and productivity. The top challenge is changing employee mindsets and corporate culture.

\section{TECHNOLOGIES FOR ABW}

Clearly, information and communication technologies have made $\mathrm{ABW}$ possible, though they must be a facilitator of $\mathrm{ABW}$, not a driver. Essential technologies include a notebook computer with ubiquitous wi-fi connectivity and phone number mobility (IP telephony). Other technologies reported by Tech Research Asia [TRA] include smart boards in workspaces, and in meeting and conference rooms, large monitors for fully engaged videoconferencing. The TRA study noted several other IT-related consequences of ABW including a need for increased data security, up to $90 \%$ reduction in printing and paper document storage, and better risk management due to the digitization of documents. Cloud computing was not a significant factor in ABW technology, though it does support increased mobility. Share point software was frequently cited as the mechanism for document sharing.

\section{The RESEARCH EXCHANGE: A COLlaborative WORKSPACE}

One notable project to promote interdisciplinary collaboration and exchange within a university is the Research Exchange at the University of Warwick [9]. This space was designed to provide innovative alternative office environments for academics and researchers, including an open-plan study space, breakout areas and an enclosed seminar space within the university library. The study looked at interactions, concentration and noise levels, where most users reporting satisfaction with the conventions surrounding conversations and mobile phone usage. Some users reported that it was "too quiet," discouraging even the briefest of exchanges. Overall, the authors of the case study report that the project is a success in terms of occupancy and user satisfaction. In fact, researchers with their own allocated office space came to work there, because of its attractive study environment. There was no discussion in the study about how teaching faculty viewed or used the Research Exchange, nor about the experiences of non-research students.

\section{FACUlTy ENVIRONMENTS IN THE UK}

In 2008, The Higher Education Funding Council for England's (HEFCE) Leadership, Governance and Management Fundan 18-month project involving Loughborough University, Nottingham Trent University, and the University of Leicester [10]. The objective of the project was to study faculty environments and identify lessons learned and best practices among member institutions. Through a series of forums, workshops, and case studies, they have developed best practices guidelines for implementing academic workspaces in the $21^{\text {st }}$ century. Their advice draws on the study of twelve buildings, and emphasizes that space is only part of the equation, that process and faculty involvement are essential, and that a pilot project is necessary. They also suggest that a "user guide" is 
frequently overlooked, as it is assumed faculty will know how to use a new office space. However, new spaces may require new ways of working and adoption of new technologies, so a user guide can help occupants to understand the design and work principles that drove the design.

\section{OPPORTUNITIES FOR ABW IN HighER EDUCATION}

Although there is a dearth of literature about $\mathrm{ABW}$ adoption in higher education, the practice appears to be well-suited to the collaboration and knowledge-work that occurs in universities. Typical professorial activities that take place outside of a classroom include:

- Administration

- Advising

- Classroom preparation

- Evaluating student work

- Home base activities - space related

- Meetings/Conferences with students, faculty, and staff

- Personal activities - quiet space, eating, etc.

- Reading

- Research

- Teaching

- Tutoring

- Writing

Aside from the important aspect of "home base," being a physical space where faculty keeps books, materials, and personal artifacts, these activities can be conducted in a variety of ABW type workspaces.

For example, committee meetings and student tutoring sessions can occur in informal meeting spaces, enclosed meeting rooms, or rooms with writable surfaces; reading, research and writing can be done in quiet reading areas; activities that demand focused concentration can take place in private cabins, while open workspaces are appropriate for administrative duties, memo-writing, email processing.

\section{PREPARING FOR ABW}

A review of best practices in $\mathrm{ABW}$ projects highlights the necessity of a pilot project as well as transparency. ABW is not an end goal, and it should not be seen simply as a cost-saving strategy. The pilot project should include the client (faculty), designers (space and technology experts) and a project team that establishes and monitors the projects and identifies risks. Other needs include:

- Secure storage for personal and work items

- Work performance uncoupled from presence

- Coffee/tea provided in informal meeting space

- Analysis of work styles and needs

- Phone number mobility (IP phones)

- A change management process with a senior champion

- A fresh, inviting space

\section{CONCLUSION}

New ways of teaching and learning, financial pressures, technology, and environmental concerns are drivers of significant change in academia. Instructors are embracing student centered pedagogies, but few are embracing non-territorial or activity-based workspaces. Most activity-based workspaces have been developed in commercial and government organizations, and so universities should look to them for lessons learned in the development and deployment of such space. However, different working demands on faculty, such as student interaction and faculty collaboration put unique requirements on workspaces that afford privacy and quiet along with collaboration and instruction. We can expect incremental change rather than transformational change, and sharing ideas, best practices, lessons learned (failures as well as successes) will help academics move from the "ivory tower" to open, non-territorial activity based workspaces.

Faculty office space is an emotional, controversial and sensitive issue. A recurring theme in the discussions of organizational $\mathrm{ABW}$ projects is the culture change that needs to be nurtured for a successful transition. Implementation and research of exploratory alternative workspace projects will further the evolution of faculty work environments that ultimately yield optimal benefits to academia.

\section{REFERENCES}

[1] Lavanchawee Sujarittanonta, Personal correspondence, April, 2012.

[2] Faculty Offices and Research Labs. University of Maryland. College of Information Studies. [Online]. Available: http://ischool.umd.edu/content/faculty-offices-and-research-labs

[3] The Faculty Office. DLC+A website. [Online]. Available: http://www.dlca.com/articles/faculty.html

[4] Buildings and Grounds, blog. Chronicle of Higher Education. [Online]. Available: https://chronicle.com/blogs/buildings/

[5] J. Pinder, J. Parkin, S. Austin, F. Duggan, M. Lansdale, P. Demian, T. Baguley, and S. Allenby, The case for new academic workspaces, Loughborough University, 2009.

[6] Bologna Process-European Higher Education Area: Student Centred Learning. [Online]. Available: www.ehea.i nfo/article-details.aspx?ArticleId $=147$

[7] A. M. Kuntz, "Reconsidering the workplace: Faculty perceptions of their work and working environment," Studies in Higher Education, vol. 37, no. 7, pp. 769-782, Jul. 2011.

[8] T. Clarke. (March, 2013). Activity based working and business outcomes in Australia, Tech Research Asia. [Online]. Available: techresearch.asia.

[9] Promoting interdisciplinary collaboration: A brief case study of the Warwick Research Exchange. University of Warwick. [Online]. Available: www2.warwick.ac.uk/services/library/researchexchange

[10] The Case for New Academic Workspaces. academicworkspace.com. [Online]. Available: http://academicworkspace.com/

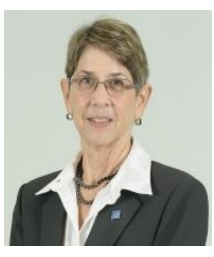

Dolly Samson earned a Ph.D. in information technology from George Mason University, Fairfax, Virginia, USA (1999), an MBA and BS Mathematics from the University of Washington, Seattle, USA (1974, 1976). With nearly forty years on the Internet, she has a rich background in its development and culture. She has worked as a software developer in aerospace, real estate and county government, served USAID appointments in Jordan, Sudan, and Lithuania and lectured in many countries in Europe and Asia. Dr. Samson was recognized with the 2007 Hawaii High-Tech Educator of the Year award by the Pacific Technology Foundation. She now serves as Assistant President for Academics, Undergraduate Programs, and lectures in information technology at Stamford International University in Bangkok, Thailand, and is an adjunct lecturer at National Economics University, Hanoi, Vietnam. 